\title{
Genomic in situ hybridization (GISH) and RFLP analysis for the identification of alien chromosomes in the backcross progeny of potato $(+)$ tomato fusion hybrids
}

\author{
E. JACOBSEN*†, J. H. DE JONG $\ddagger$, S. A. KAMSTRA $\ddagger$, P. M. M. M. VAN DEN BERG $\dagger$ \& \\ M. S. RAMANNA $\dagger$ \\ The Graduate School of Experimental Plant Sciences, $\uparrow$ Department of Plant Breeding and $\ddagger$ Department of Genetics, \\ Wageningen Agricultural University, The Netherlands
}

\begin{abstract}
Backcross progenies, $\mathrm{BC} 1$ and $\mathrm{BC} 2$, derived from crossing a hexaploid potato $(+)$ tomato fusion hybrid to tetraploid potato, were monitored for the presence of alien tomato chromosomes. For discriminating the tomato chromosomes from those of potato, both mitotic and meiotic chromosome preparations were labelled differentially through total genomic DNA in situ hybridization (GISH). The presence or absence of individual tomato chromosomes in the BC progeny was identified through RFLP analyses using chromosome-specific DNA probes. The results indicated that the $\mathrm{BC} 1$ plant possessed only nine chromosomes of tomato instead of the expected haploid set of 12 . Of the nine persistent tomato chromosomes, there were three pairs that formed bivalents and three singles that formed univalents at meiosis. One of the single chromosomes was strikingly longer as a result of some structural mutation and could easily be identified in the hexaploid parent, the $\mathrm{BC} 1$ and in some of the $\mathrm{BC} 2$ plants. From the analyses of $\mathrm{BC} 2$ progeny there were indications of the presence in the $\mathrm{BC} 1$ of tomato chromosomes 1,3 and 6 in duplicate, and chromosomes 8,9 and 10 in the haploid condition. The number of tomato chromosomes transmitted to $\mathrm{BC} 2$ plants varied from one to six. The results of GISH revealed that a few BC2 plants possessed more tomato chromosomes than those deduced from RFLP analysis. This indicated the presence of some tomato chromosomes in duplicate and others in the haploid condition. The potential value of these genotypes for establishing potato lines with additions and substitutions of tomato chromosomes is discussed.
\end{abstract}

Keywords: alien chromosome addition, backcross progeny, GISH, Lycopersicon esculentum, Solanum tuberosum, somatic hybrids.

\section{Introduction}

Somatic hybridization through protoplast fusion (Melchers et al., 1978) offers the potential for utilizing distantly related taxa in crop breeding. Unlike sexual hybridization, through protoplast fusion it should be possible to exploit individual organelle genomes in addition to the nuclear genome. With this aim, somatic fusion hybrids between potato and tomato have been successfully made in the past (Shepard et al., 1983; Wolters et al., 1991; Jacobsen et al., 1992; Schoenmakers et al., 1994). If such somatic hybrids are to be used further in breeding, the following aspects have to

\footnotetext{
${ }^{*}$ Correspondence.
}

be considered: (i) the possibility of backcrossing the fusion hybrid to the parents; (ii) the transmission of the individual genomes, or individual chromosomes from somatic hybrids to the progeny in the subsequent generations; (iii) the occurrence and extent of any genetic recombination between the homoeologous chromosomes; (iv) the structural integrity of individual chromosomes in an alien genomic background and the possibility of producing lines with alien chromosome additions and/or substitutions from either the potato or the tomato.

To answer these basic questions as well as to develop breeding material, hexaploid potato $(+)$ tomato somatic fusion hybrids $(2 n=6 x=72)$ were successfully backcrossed to tetraploid potato 
$(2 n=4 x=48)$ for the first time (Jacobsen et al., 1994 and unpublished). The resulting backcross progeny, $\mathrm{BC} 1$ and $\mathrm{BC} 2$, were analysed cytologically for their chromosome constitution using the technique of total genomic DNA in situ hybridization (GISH) that has successfully been applied to several other plant species (Anamthawat-Jónsson et al., 1990, 1993; Schwarzacher et al., 1992; Kenton et al., 1993; Mukai et al., 1993). Besides this cytological study, the presence or absence of alien individual tomato chromosomes in the BC progeny was identified through RFLP analysis using chromosome-specific DNA probes.

\section{Materials and methods}

\section{Plant material}

For protoplast fusion, the diploid potato, Solanum tuberosum $(87.1017 / 5,2 n=2 x=24)$, heterozygous for the amylose-free locus (Amflamf, Jacobsen et al., 1989 ), was used as one of the parents. The other parent was Lycopersicon esculentum $(2 n=2 x=24)$, mutant C31, deficient for nitrate reductase (Schoenmakers et al., 1991). The resulting somatic fusion hybrid, C31-17-1, was a hexaploid $(2 n=6 x=72)$. Dot blot analysis had revealed that this fusion hybrid possessed four genomes of potato and two of tomato (Jacobsen et al., 1994).

The first backcross progeny was produced by crossing C31-17-1 to the $4 x$-potato clone AM66-42 and the near-pentaploid $(2 n=5 x-3=57) \mathrm{BC} 1$ plant, 93.6701, was obtained (Jacobsen et al., 1994). The $\mathrm{BC} 2$ plants originated from a cross between 93.6701 and the $4 x$-potato clone $90.6020 / 22$, which is nulliplex for the amf locus (Jacobsen et al., 1994). The following $\mathrm{BC} 2$ progeny were included in this investigation: $93.6731 / 1 ;-/ 2 ;-/ 3 ;-/ 4 ;-/ 5 ;-/ 6 ;-/ 7 ;-/ 9 ;-/ 11 ;-/ 14$; $-/ 19 ;-/ 22$ and $-/ 24$. All plants were maintained as in vitro cultures as well as grown in the greenhouse for collecting root tips and leaf samples.

\section{DNA probes for RFLP analysis}

In all, 12 different DNA probes that could specifically identify each of the 12 tomato chromosomes were used. The probes corresponding to potato and tomato chromosomes in the order of 1 to 12 were the following: Ssp55; Ssp38; TG130; Ssp27; GP21; TG118; TG143; GBSS; TG89; TG28; Ssp29; and Ssp129. The probes were kindly provided by: $T G=S$. D. Tanksley, Ssp $=$ C. M. Kreike, GP=C. Gebhardt, GBSS = R. G. F. Visser.

For RFLP analysis, DNA was extracted from young shoots and leaves according to Bernatsky \& Tanksley
(1986). The procedures for restriction digestion and Southern hybridization were according to Kreike et al. (1990) and van Eck et al. (1993).

\section{Genomic in situ hybridization}

Fast growing root tips were pretreated in an aqueous solution of $2 \mathrm{~mm} 8$-hydroxyquinoline for $2-2.5 \mathrm{~h}$ at $17^{\circ} \mathrm{C}$ and fixed in a solution of $3: 1$ ethanol: acetic acid at room temperature for 4-6 h. The fixed root meristems were thoroughly washed in water and incubated in a pectolytic enzyme mixture $(0.1$ per cent pectolyase Y23, 0.1 per cent cellulase RS and 0.1 per cent cytohelicase in $10 \mathrm{~mm}$ citrate buffer, $\mathrm{pH} \mathrm{4.5)}$ for $1 \mathrm{~h}$ at $37^{\circ} \mathrm{C}$. The material was carefully transferred on to a grease-free microscope slide and the cells were spread according to the technique of Pijnacker \& Ferwerda (1984). For preparations of meiotic cells we selected anthers with pollen mother cells at the appropriate meiotic stages by monitoring one squashed anther in a drop of aceto-carmine, examining it under a phase contrast microscope and fixing the remaining anthers in acetic alcohol fixative. Anthers with pollen mother cells were digested with the same pectolytic enzyme mixture although the concentration was three times higher ( 0.3 per cent each), and the incubation time at $37^{\circ} \mathrm{C}$ was increased to $2-3 \mathrm{~h}$.

The procedures of DNA denaturation, in situ hybridization and detection/amplification were according to Leitch \& Heslop-Harrison (1994), Schwarzacher \& Heslop-Harrison (1994) and Schwarzacher \& Leitch (1994). The tomato DNA was sonicated until the fragments attained the size of 1-10 $\mathrm{kb}$ and labelled with digoxigenin-11-dUTP or Fluorescein-11-dUTP according to a standard random primed labelling protocol. The potato DNA was autoclaved for 5 min giving fragments of about $100 \mathrm{bp}$. The hybridization mix ( $40 \mu \mathrm{L}$ per slide) consisted of 50 per cent deionized formamide 10 per cent $(w / v), 20$ per cent sodium dextran sulphate (Sigma), $2 \times$ SSC, 0.25 $(\mathrm{w} / \mathrm{v})$ sodium dodecyl sulphate, $2.5 \mathrm{ng} / \mu \mathrm{L}$ probe DNA and $0.1-0.25 \mu \mathrm{g} / \mu \mathrm{L}$ blocking DNA. This mix was denatured for $10 \mathrm{~min}$ at $90^{\circ} \mathrm{C}$ and then placed on ice for five minutes. Hybridization was performed overnight at $37^{\circ} \mathrm{C}$ and the slides were then washed in $2 \times \mathrm{SSC}$ buffer for $30 \mathrm{~min}$. at $20^{\circ} \mathrm{C}$, in $0.1 \times \mathrm{SSC}$ for 30 min at $42^{\circ} \mathrm{C}$ followed by $2 \times \mathrm{SSC}$ again for $15 \mathrm{~min}$ at $20^{\circ} \mathrm{C}$. In the case of labelling with digoxigenin, we performed detection with anti-digoxigenin-FITC raised in sheep (Boehringer-Mannheim) and amplified with anti-sheep-FITC raised in rabbit (Nordic Immunological Laboratories). Chromosomes were in all cases counter-stained with $2 \mu \mathrm{g} / \mathrm{mL}$ DAPI (4'6-diaminidine-2-phenylindole) and 1-5 $\mu \mathrm{g} / \mathrm{mL}$ propidium iodide and mounted in $10 \mu \mathrm{L}$ antifade 
solution containing 2.5 per cent $\mathrm{DABCO}(1,4-\mathrm{Diazabi}$ cyclo[2.2.2.]octane (Sigma) in glycerol). Selected nuclei were photographed on 400 ISO colour negative film.

\section{Results}

The karyotypes of tomato and potato are very similar, so that most chromosomes cannot be discriminated in the fusion hybrids and backcross derivatives through the routine cytological procedures such as Feulgen or carmine staining or even the C-banding technique. Therefore, special cytological and molecular procedures were required to characterize the chromosome constitutions of the fusion hybrid and the $\mathrm{BC}$ progeny. To this end, it was essential to make use of the GISH technique and RFLP analysis.

\section{Chromosome constitution of C31-17-1}

Although the hexaploid C31-17-1 was known to possess four genomes of potato and two of tomato (Jacobsen et al., 1994), the evidence was indirect. Therefore, a more direct cytological estimate was made through GISH (Fig. 1a). As expected, there was unequivocal evidence for the presence of two complete tomato genomes which fluoresce yellow or green using FITC-labelled tomato DNA hybridized as probe. A notable feature was the presence of an extra-long chromosome easily detectable in nuclei at prophase and prometaphase stages in this plant. This abnormality was probably the result of chromosomal rearrangements induced either during the fusion process or tissue culture during the callus phase or regeneration. Besides cytological evidence for the presence of two complete genomes, RFLP analysis confirmed that all the twelve tomato chromosomes were represented in the fusion hybrid (Table 1).

\section{Anomalous chromosome constitution of the BC1 plant}

In the root tip cells of this plant the chromosome number was found to be $2 n=5 x-3=57$. This shortage of three chromosomes from the expected pentaploid $(2 n=5 x=60)$ number could have resulted from nontransmission of either potato or tomato chromosomes from the fusion hybrid to the $\mathrm{BC} 1$ progeny. Alternatively, chromosome elimination could be the cause of the aneuploidy observed. In order to establish the chromosome constitution of this $\mathrm{BC} 1$ (93.6701), (i) the somatic chromosomes were differentially labelled through GISH, (ii) chromosome pairing was analysed in pollen mother cells following GISH and (iii) the presence or absence of individual tomato chromosomes was determined through RFLP analysis using chromosome-specific DNA probes.

(i) The somatic chromosome complement included nine differentially labelled tomato chromosomes (Fig. 1b). Among these nine chromosomes, one was abnormally long (arrow in Fig. 1B), which was equivalent to the one observed in the fusion hybrid C31-17-1. With the exception of the aberrant chromosome, it was impossible to determine whether the differentially labelled bodies represented eight different chromosomes of tomato or not. However, meiotic analysis helped to resolve the chromosome constitution of BC1.

(ii) If all the alien chromosomes retained in the $\mathrm{BC} 1$ plant were nonhomologues, nine univalents would be observed during the prophase to metaphase I stages of meiosis. However, contrary to this expectation, three tomato bivalents and three tomato univalents were detected at pachytene and diakinesis/metaphase I (Fig. $1 \mathrm{c}, \mathrm{d})$. This was a clear indication of the presence of three homologous pairs of tomato chromosomes and three univalents accounting for a total of nine alien chromosomes in 93.6701. Thus the nine chromosomes represented only six of the 12 chromosomes of the haploid complement of tomato expected to be present in the $\mathrm{BC} 1$ plant. Except for counting the number of bivalents and univalents, it was not possible to identify which of the tomato chromosomes were present in the $\mathrm{BC} 1$ plant. However, the extra long tomato chromosome could be identified as one of the univalents (Fig. $1 \mathrm{~d}$, arrow). For the identification of individual

Fig. 1 Genomic in situ hybridization to mitotic and meiotic cell spreads of somatic tomato (+) potato hybrids and BC1 and $\mathrm{BC} 2$ derivatives. Yellow-green fluorescence shows hybridization to the total genomic DNA tomato probe. Unlabelled chromatin fluoresces red with propidium iodide.

(a) Somatic metaphase chromosomes of the fusion hybrid, C31-17-1 (2n=6x=72) showing 24 chromosomes of tomato and 48 of potato. Scale bar equals $10 \mu \mathrm{m}$.

(b) Somatic metaphase chromosomes of the BC1,93.6701 $(2 n=5 x-3=57)$, showing only nine green fluorescing tomato chromosomes instead of the expected 12 . The extra long tomato chromosome is indicated (arrow).

(c) Pollen mother cell at pachytene of the BC1, 93.6701, showing three differentially labelled bivalents (II) and three univalents

(I) of the tomato.

(d) Pollen mother cell at diakinesis of the BC1 showing three bivalents (II) and three univalents (I). The conspicuous chromosome represents the abnormally long tomato chromosome.

(e,f) Somatic metaphase complements of two BC2 plants showing three and four tomato chromosomes of which one has the abnormally long tomato chromosome (arrow). 

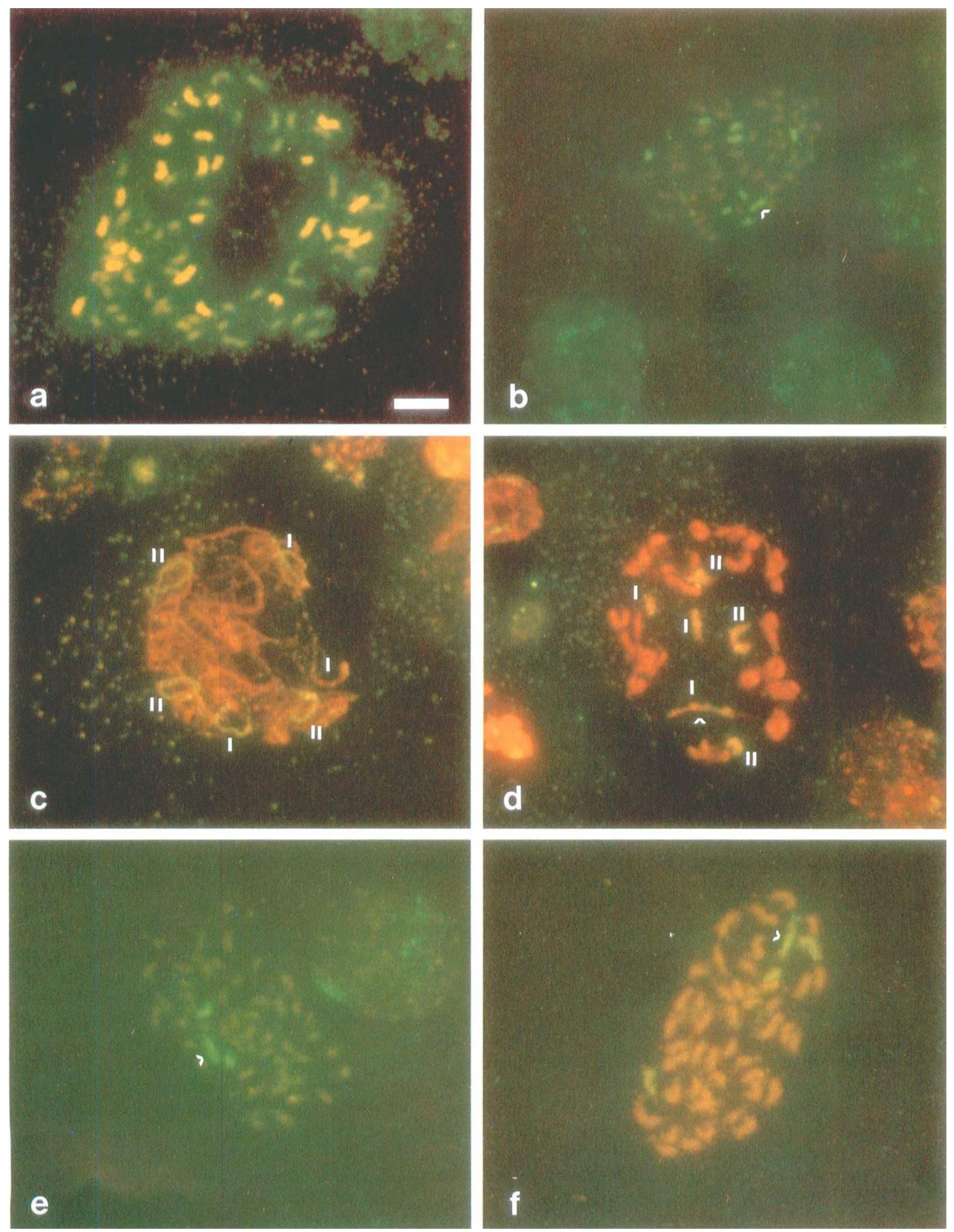
Table 1 The number of tomato chromosomes detected through GISH and identified through RFLP analysis in the fusion hybrid, $\mathrm{BC} 1$ and $\mathrm{BC} 2$ progenies

\begin{tabular}{|c|c|c|c|c|c|c|c|c|c|c|c|c|c|}
\hline \multirow[b]{3}{*}{ Chromosome } & \multirow[b]{3}{*}{ Probe } & \multicolumn{2}{|c|}{ Parents } & \multirow{3}{*}{$\begin{array}{c}\begin{array}{c}\text { Somatic } \\
\text { hybrid }\end{array} \\
\text { C31-17-1 }\end{array}$} & \multirow{3}{*}{$\frac{\mathrm{BC} 1}{93.6701}$} & \multirow{2}{*}{\multicolumn{8}{|c|}{ BC2 plants \# (93.6731) }} \\
\hline & & \multirow{2}{*}{$\frac{\text { Tomato }}{\text { C31 }}$} & \multirow{2}{*}{$\frac{\text { Potato }}{87.1017 / 5}$} & & & & & & & & & & \\
\hline & & & & & & 1 & 2 & 3 & 4 & 5 & 6 & 9 & 14 \\
\hline 1 & Ssp55 & + & - & + & + & + & + & - & - & + & + & - & - \\
\hline 2 & Ssp38 & + & - & + & - & - & - & - & - & - & - & - & - \\
\hline 3 & TG130 & + & - & + & + & + & + & + & + & - & + & - & - \\
\hline 4 & Ssp27 & + & - & + & - & - & - & - & - & - & - & - & - \\
\hline 5 & Gp21 & + & - & + & - & - & - & - & - & - & - & - & - \\
\hline 6 & TG118 & + & - & + & + & + & + & + & + & + & + & + & + \\
\hline 7 & TG143 & + & - & + & - & - & - & - & - & - & - & - & - \\
\hline 8 & GBSS & + & - & + & + & - & - & - & - & - & - & + & - \\
\hline 9 & TG8 & + & - & + & + & + & - & - & + & - & - & - & - \\
\hline 10 & TG285 & + & - & + & + & - & - & + & - & + & - & - & - \\
\hline 11 & Ssp29 & + & - & + & - & - & - & - & - & - & - & - & - \\
\hline \multirow[t]{4}{*}{12} & Ssp129 & + & - & + & - & - & - & - & - & - & - & - & - \\
\hline & RFLP: & 12 & 0 & 12 & 6 & 4 & 3 & 3 & 3 & 3 & 3 & 2 & 1 \\
\hline & GISH: & 24 & 0 & 24 & 9 & 4 & 3 & 3 & 3 & 3 & n.d. & 2 & 1 \\
\hline & $2 n=$ & 24 & 24 & 72 & 57 & 52 & 51 & 51 & 53 & 54 & - & 50 & 49 \\
\hline
\end{tabular}

+ indicates the presence and - the absence, respectively, of tomato chromosomes for which they were tested with chromosome-specific probes. n.d.: not determined.

chromosomes of tomato RFLP analysis was carried out.

(iii) Corresponding to the cytological observation, RFLP analysis identified only six of the possible 12 chromosomes of tomato (Table 1). This means the chromosome-specific probes that had identified all the 12 tomato chromosomes in the fusion hybrid, C31-171 , gave positive results for six of the chromosomes: 1 , $3,6,8,9$ and 10 , the rest being absent from the $\mathrm{BC} 1$ plant. Although the presence of individual chromosomes of tomato in the $\mathrm{BC} 1$ plant could be confirmed through RFLP analysis, it was not possible to establish which of the three chromosomes were present in pairs. This could be tentatively determined through the analysis of the $\mathrm{BC} 2$ progeny.

\section{Analysis of $B C 2$ progeny}

A total of twelve different $\mathrm{BC} 2$ plants were analysed in order to determine the number of tomato chromosomes still persistent in the somatic cells. These genotypes were: $93.6731-1,-2,-3,-4,-5,-7,-9,-11,-14$, $-19,-22$ and -24 . In all cases, in addition to 48 chromosomes of potato, the presence of variable numbers of tomato chromosomes could be demonstrated through GISH (Fig. 1e,f and Table 1). Between plants, the number of alien tomato chromosomes varied from 1 to 6 . Within a plant, however, the number remained fairly constant between different somatic cells. The abnormally long chromosome observed in the fusion hybrid and $\mathrm{BC} 1$ was transmitted to some of the $\mathrm{BC} 2$ progeny (e.g. 6731-1 and -22). Chromosome pairing has not been analysed in any of these plants so far.

RFLP analysis was carried out in eight $\mathrm{BC} 2$ plants. As expected, only those alien tomato chromosomes that were present in the $\mathrm{BC} 1$ plant reappeared in the $\mathrm{BC} 2$ progeny (Table 1). A remarkable feature was that some of the alien chromosomes were present more frequently than others. For example, chromosome 6 of tomato was present in all the eight $\mathrm{BC} 2$ progeny that were analysed and even in 12 additional plants tested for this chromosome (unpublished results). In addition, chromosomes 1 and 3 were observed more frequently than the other three chromosomes, namely 8,9 and 10 . This might indicate that those chromosomes which were present in the disomic condition in the $\mathrm{BC} 1$ were transmitted at a higher frequency to the $\mathrm{BC} 2$ progeny than those that were present in the monosomic condition. If this were the case, then the more frequently encountered chromosomes would be more likely to be present as homologous pairs than the rest. The trans- 
mission of chromosome 6 was observed in all $20 \mathrm{BC} 2$ plants indicating normal disomic inheritance for this chromosome.

In seven BC2 plants the presence of tomato chromosomes was tested both by chromosome-specific probes and GISH (Table 1). The results in five of them were consistent. In the other two, 93.6731-4 and 93.6731-5, as in the BC1 93.6701, there was a difference between the number of tomato chromosomes detected through RFLPs and through GISH (Table 1). In both cases, RFLP analyses identified three chromosomes each but GISH revealed the presence of five and six chromosomes respectively. This means that in these two $\mathrm{BC} 2$ plants, as in $\mathrm{BC} 1,93.6731$, some of the chromosomes were present in the disomic and the others in the monosomic condition. This anomalous chromosome constitution has obviously resulted from irregular chromosome segregation during meiosis in the $\mathrm{BC} 1$.

\section{Discussion}

This study shows that tomato chromosomes can easily be discriminated from those of potato through the technique of GISH. The detection of tomato chromosomes is consistent and reliable for the following reasons. (i) Based on dot blot hybridization it was concluded that two genomes of tomato are present in the hexaploid somatic hybrid, C31-17-1 (Jacobsen et al., 1994). The results of GISH also indicate the presence of two genomes of tomato in this fusion hybrid (Fig. 1a). (ii) In the BC1 plant only nine of the expected 12 chromosomes of tomato were detected (Fig. 1b) of which three were present in the disomic condition (Fig. 1c). This cytological evidence suggests the presence of only six individual tomato chromosomes in the $\mathrm{BC} 1$ plant. The RFLP data vindicate (Table 1) the cytological observations. (iii) Furthermore, RFLP analyses of $\mathrm{BC} 2$ progeny confirm the presence of only six chromosomes in the $\mathrm{BC} 1$ plant.

Accurate detection and identification of alien chromosomes in the backcross progeny is an important prerequisite for successful introgression of chromosomes from distantly related taxa into crop plants. In crops such as potato and tomato that possess very small chromosomes, their accurate identification through traditional cytogenetic methods is difficult, if not impossible. In this context, chromosome identification through GISH and RFLP analysis, as has been demonstrated in this study, offers attractive possibilities for chromosome and gene introgression even among Solanaceous taxa. Addition of either single or pairs of intact alien chromosomes does not require homoeologous recombination to occur in the fusion hybrids or their progeny. The BC2 plants included in this study (Table 1) are potentially useful for creating monosomic or disomic potato/tomato addition lines.

Although they are intergeneric hybrids the parental species, potato and tomato, possess some common cytogenetic features. First, their chromosomes are morphologically similar (Yeh \& Peloquin, 1965; Ramanna \& Wagenvoort, 1976); second, their molecular linkage maps are nearly homosequential (Tanksley et al., 1992) and third, homoeologous chromosome pairing and recombination might occur in fusion hybrids (de Jong et al., 1993). In view of these observations it is likely that besides monosomic and disomic alien lines, it might be possible to recover genotypes with recombinant chromosomes. The recovery of such alien chromosome recombinants through the help of GISH has been demonstrated in the case of cereals (Anamthawat-Jónsson et al., 1990; King et al., 1993, 1994; Mukai et al., 1993) and tobacco (Kenton et al., 1993). Tentative studies (Wolters et al., 1994) showed similar recombinants in the case of potato $(t)$ tomato fusion hybrids as well.

Once the monosomic or disomic alien addition lines are established, the questions remaining are: (a) whether the added chromosomes are retained in the alien genetic background without being preferentially eliminated and (b) whether the structural integrity of the alien chromosome remains intact in the new genetic background. In an earlier study (Shepard et al., 1983) preferential elimination of alien chromosomes in potato $(t)$ tomato fusion hybrids has been recorded. In this case chromosome elimination was inferred solely on the basis of the chromosome counts which fell short of the expected number. In any case the eliminated chromosomes were not identified. With the identification method used in this study chromosome elimination, when it occurs, can be accurately monitored. Besides this cytological method, chromosome elimination can also be detected through the use of the amf marker gene used in this study. Because the wild type Amf-locus marks chromosome 8 of tomato, the elimination of this chromosome from a simplex genotype (Amf/amf/amf/amf) can be easily detected by staining any starch-containing tissue with iodine which gives a red colouration. The advantage of this method is that even low frequencies of chromosome elimination can be estimated with little effort when the appropriate genotypes are used.

The absence of three tomato chromosomes in the BC1 plant, 93.6701 is intriguing. Because the fusion hybrid C31-17-1 possesses two complete sets of the tomato chromosomes, a balanced haploid set of 12 chromosomes from this parent was expected to be present in the $\mathrm{BC} 1$. Contrary to this, three pairs 
(probably chromosomes 1, 3 and 6) and three monosomics (probably 8,9 and 10) from the fusion hybrid have been transmitted in the functional gamete. There is no clear explanation at present for the occurrence of such an anomalous cytological event in the fusion hybrid. However, observations of pollen mother cells at anaphase II in some other somatic tomato $(+)$ potato hybrid cells revealed very skewed segregations of the tomato chromosomes in the daughter cells (unpublished work). Whether this anomaly in the meiosis of hexaploid fusion hybrids is rare or a more regular feature will be evident after the analysis of the second $\mathrm{BC} 1$ progeny that we have produced recently (unpublished). In the $\mathrm{BC} 2$, strong indications for the same kind of anomalous transmission of single and pairs of alien chromosomes, using the $\mathrm{BC} 1$ as female, have been found.

\section{Acknowledgements}

We thank the following persons for contributing their knowledge, skills and technical assistance during this investigation: Ir. Herman van Eck, Mr. Dirk-Jan Huigen, Ms. Marian Bergervoet and Ms. Jannie van Eden.

\section{References}

ANAMTHAWAT-JONSSON, K., SCHWARZACHER, T., LEITCH, A. R., BENNETT, M. D. AND HESLOP-HARRISON, J. S. 1990. Discrimination between closely related Triticaea species using genomic DNA as a probe. Theor. Appl. Genet., 79, 721-728.

BERNATSKY, R. AND TANKSLEY, S. D. 1986. Toward a saturated linkage map in tomato based on isozyme and random cDNA sequences. Genetics, 112, 887-898.

VAN ECK, H. J., JACOBS, J. M. E., VAN DIJK, J., STIEKEMA, W. J. AND JACOBSEN, E. 1993. Identification and mapping of three flower colour loci of potato (S. tuberosum L.) by RFLP analysis. Theor. Appl. Genet., 86, 295-300.

JOCOBSEN, E., HOVENKAMP-HERMELINK, J. H. M., KRIJGSHELD, H. T., NIJDAM, H., PIJNACKER, L. P., WITHOLD, B. AND FEENSTRA, W. J. 1989. Phenotypic and genotypic characterisation of an amylose-free starch mutant of potato. Euphytica, 44, 43-48.

JACOBSEN, E., REINHOUT, P., BERGERVOET, J. E. M., DE LOOFF, J., ABIDIN, P. E., HUIGEN, D. J. AND RAMANNA, M. S. 1992. Isolation and characterization of potato-tomato somatic hybrids using an amylose-free potato mutant as parental genotype. Theor. Appl. Genet., 85, 159-164.

JACOBSEN, E., DANIEL, M. K., BERGERVOET-VAN DEELEN, J. E. M., HUIGEN, D. J. AND RAMANNA, M. S. 1994. The first and second backcross progeny of the intergeneric fusion hybrids of potato and tomato after crossing with potato. Theor. Appl. Genet., in press.

DE JONG, J. H., WOLTERS, A. M. A., KOK, J. M., VERHAAR, H. AND VAN EDEN, J. 1993. Chromosome pairing and potential for intergeneric recombination in some hypotetraploid somatic hybrids of Lycopersicon esculentum (+) Solanum tuberosum. Genome, 36, 1032-1041.

KENTON, A., PAROKONNY, A. S., GLEBA, Y. Y. AND BENNETT, M. D. 1993. Characterization of the Nicotiana tabacum $\mathbf{L}$. genome by molecular cytogenetics. Mol. Gen. Genet., 240, 159-169.

KING, I. P., PURDIE, K. A., ORFORD, S. E., READER, S. M. AND MILLER, T. E. 1993. Detection of homoeologous chiasma formation in Triticum durum $\times$ Thinopyrum bessarabicum hybrids using genomic in situ hybridization. Heredity, 71, 369-372.

KING, I. P., READER, S. M., PURDIE, K. A., ORFORD, S. E. AND MILLER, T. E. 1994. A study of the effect of a homoeologous pairing promoter on chromosome pairing in wheat/rye hybrids using genomic in situ hybridization. Heredity, 72, 318-321.

KREIKE, C. M., KoNING, J. R. A., DE KRENS, F. A. 1990. Non-radioactive detection of single-copy DNA-DNA hybrids. Plant Mol. Biol. Rep., 8, 172-179.

LEITCH, I. J. AND HESLOP-HARRISON, J. S. 1994. Detection of digoxigenin labelled DNA probes hybridized to plant chromosomes in situ. In: Isaac, P. G. (ed.) Methods in Molecular Biology, vol. 28: Protocols for Nucleic Acid Analysis by Non-radioactive Probes, pp. 18-25. Humana Press Inc., Totowa, NJ.

MELCHERS, G., SACRISTAN, M. D. AND HOLDER, A. A. 1978. Somatic hybrid plants of potato and tomato regenerated from fused protoplasts. Carlsberg Res. Comm., 43, 203-218.

MUKAI, Y., NAKAHARA, Y. AND YAMAMOTO, M. 1993. Simultaneous discrimination of the three genomes in hexaploid wheat by multicolor fluorescence in situ hybridization using total genomic and highly repeated DNA probes. Genome, 36, 489-494.

PIJNACKER, L. P. AND FERWERDA, M. A. 1984. Giemsa C-banding of potato chromosomes. Can. J. Genet. Cytol., 26, 415-419.

RAMANNA, M. S. AND WAGENVOORT, M. 1976. Identification of the trisomic series in diploid Solanum tuberosum L., Group Tuberosum. I. Chromosome identification. Euphytica, 25, 233-240.

SCHOENMAKERS, H. C. H., KOORNNEEF, M., ALEFS, S. J. H. M., GERRITS, W. F. M., VAN DER KOP, D., CHÉREL, I. AND CABOCHE, M. 1991. Isolation and characterization of nitrate reductasedeficient mutants in tomato (Lycopersicon esculentum Mill). Mol. Gen. Genet., 227, 458-464.

SCHOENMAKERS, H. C. H., WOLTERS, A. M. A., NOBEL, E. M., DE KLEIN, C. M. J. AND KOORNNEEF, M. 1994. Allotriploid somatic hybrids of diploid tomato (Lycopersicon esculentum Mill) and monoploid potato (Solanum tuberosum L.). Theor. Appl. Genet., 87, 328-336.

SCHWARZACHER, T., ANAMTHAWAT-JONSSON, K., HARRISON, G. E. ISLAM, A. K. M. R., JIA, J. Z., KING, I. P., LEITCH, A. R., MILLER, T. E., READER, S. M., ROGERS, W. J., SHI, M. AND HESLOP-HARRISON, J. S. 1992. Genomic in situ hybridization to identify alien chromosomes and chromosome segments in wheat. Theor. Appl. Genet., 84, 778-786.

SCHWARZACHER, T. AND HESLOP-HARRISON, J. s. 1994. Direct fluorochrome labelled DNA probes for direct fluorescent 
in situ hybridization to chromosomes. In: Isaac, P. G. (ed.) Methods in Molecular Biology, vol. 28: Protocols for Nucleic Acid Analysis by Non-radioactive Probes, pp. 8-17. Humana Press Inc., Totowa, NJ.

SCHWARZACHER, T. AND LEITCH, A. R. 1994. Enzymatic treatment of plant material to spread chromosomes for in situ hybridization. In: Isaac, P. G. (ed.) Methods in Molecular Biology, vol. 28: Protocols for Nucleic Acid Analysis by Non-radioactive Probes, pp. 2-7. Humana Press Inc., Totowa, NJ.

SHEPARD, J. F., BIDNEY, D. BARSBY, T. AND KEMBLE, R. 1983. Genetic transfer in plants through interspecific protoplast fusion. Science, 219, 683-688.

TANKSLEY, S. D., GANAL, M. W., PRINCE, J. P., DE VINCENTE, M. C., BONIERBALE, M. W., BROUN, P., FULTON, T. M., GIOVANNONI, J. J., GRANDILLO, S., MARTIN, G. B., MESSEGUER, R., MILLER, J. C., MILLER, L., PATERSON, A. H., PINEDA, O., RÖDER, M. S., WING, R. A.,
wU, w. AND YOUNG, N. D. 1992. High density molecular genetic maps of the tomato and potato genomes. Genetics, 132, 1141-1160.

WOLTERS, A. M. A., SCHOENMAKERS, H. C. H., VAN DER MEULENMUISERS, J. J. M., VAN DER KNAAP, E., DERKS, F. H. M., KOORNNEEF, M. AND ZELCER, A. 1991. Limited DNA elimination from the irradiated potato parent in fusion products of albino Lycopersicon esculentum and Solanum tuberosum. Theor. Appl. Genet., 83, 225-232.

WOLTERS, A. M. A., SCHOENMAKERS, H. C. H., KAMSTRA, S., VAN EDEN, J., DE JONG, J. H. AND KOORNNEEF, M. 1994. Mitotic and meiotic irregularities in somatic hybrids of Lycopersicon esculentum and Solanum tuberosum. Genome, in press.

YEH, B. P. AND PELOQUIN, S. J. 1965. Pachytene chromosomes of the potato (Solanum tuberosum Group Andigena). Am. J. Bot., 52, 1014-1020. 